\title{
SÍNTESE DE BIODIESEL: UMA PROPOSTA CONTEXTUALIZADA DE EXPERIMENTO PARA LABORATÓRIO DE QUÍMICA GERAL
}

\author{
Roberto Rinaldi, Camila Garcia, Letícia Ledo Marciniuk, Adriana Vitorino Rossi e Ulf Schuchardt* \\ Instituto de Química, Universidade Estadual de Campinas, CP 6154, 13083-970 Campinas - SP, Brasil
}

Recebido em 13/7/06; aceito em 10/11/06; publicado na web em 27/4/07

\begin{abstract}
SYNTHESIS OF BIODIESEL: A CONTEXTUALIZED EXPERIMENT PROPOSAL FOR THE GENERAL CHEMISTRY LABORATORY. The contextualized understanding of concepts in Chemistry by students from other areas is a challenging task. In this experiment, the synthesis of biodiesel is done by base catalyzed transesterification of refined soy oil with methanol at room temperature and common glassware found in any chemistry laboratory. The proposal permits introducing several concepts, such as that of emulsion, viscosity and catalysis to illustrate an activity based on an actual problem. In this didactic approach, some common problems of biodiesel production, such as soap formation and phase separation, are introduced into the procedure in order to raise questions and motivate the students to participate in the experimental work and stimulate reflections about critical aspects of biodiesel production. This experiment was carried out in the first semester of 2006, in experimental general chemistry taken by physics and agricultural, civil and chemical engineering students of UNICAMP.
\end{abstract}

Keywords: biodiesel; emulsion; viscosity.

\section{INTRODUÇÃO}

A história da aplicação de óleos vegetais como combustível começou em 1898 na Feira Mundial de Paris, onde Rudolf Diesel apresentou um motor abastecido com óleo de amendoim mais eficiente que os motores a vapor usados na época ${ }^{1,2}$. Entre 1911 e 1912, o já milionário inventor foi um visionário ao fazer a afirmação: "O motor a diesel pode ser alimentado por óleos vegetais $e$ ajudará no desenvolvimento agrário dos países que vierem a utilizálo... O uso de óleos vegetais como combustível pode parecer insignificante hoje em dia. Mas com o tempo (estes óleos) tornar-se-ão tão importantes quanto o petróleo e o carvão são atualmente ${ }^{{ }_{3}, 4}$. Entretanto, o óleo mineral tornou-se o combustível para esse tipo de motor desde o início do século XX, devido ao seu menor custo e a melhores propriedades físico-químicas em comparação com os óleos vegetais. O óleo mineral é comumente chamado óleo diesel em reconhecimento a R. Diesel. Atualmente, as mudanças climáticas associadas à liberação de gases da queima de combustíveis fósseis, o alto preço internacional do petróleo e a preocupação com o desenvolvimento sustentável começam a retomar a intenção original de Diesel do emprego de óleos vegetais aos motores movidos a óleo mineral ${ }^{5}$.

Os óleos vegetais são constituídos predominantemente de substâncias conhecidas como triglicerídeos (também chamadas de triacilgliceróis ou triacilglicerídeos), que são ésteres formados a partir de ácidos carboxílicos de cadeia longa (ácidos graxos) e glicerol ${ }^{6}$. Além dos triglicerídeos, os óleos vegetais apresentam em sua composição quantidades apreciáveis de ácidos graxos livres (originados dos processos de extração dos óleos vegetais), fosfolipídeos, esteróis e tocoferóis. A Tabela 1 traz a distribuição de ácidos graxos de alguns óleos e gorduras. Os ácidos graxos constituintes dos triglicerídeos mais comuns apresentam 12, 14, 16 ou 18 átomos de carbono. Entretanto, outros ácidos graxos com menor ou maior número de átomos de carbono ou ainda contendo a função álcool também podem ser encontrados em vários óleos e gorduras. Um exem-

*e-mail: ulf@iqm.unicamp.br plo interessante é o óleo de mamona, que apresenta o ácido ricinoléico, $\mathrm{CH}_{3}\left(\mathrm{CH}_{2}\right)_{5} \mathrm{CH}(\mathrm{OH}) \mathrm{CH}_{2} \mathrm{CH}=\mathrm{CH}\left(\mathrm{CH}_{2}\right)_{7} \mathrm{COOH}$, como maior constituinte de seus triglicerídeos (cerca de 80\%). Os óleos vegetais apresentam várias vantagens para uso como combustível, como elevado poder calorífico, ausência de enxofre em suas composições e são de origem renovável. Contudo, o uso direto de óleos vegetais como combustíveis para motores é problemático devido a sua alta viscosidade, maior densidade e baixa volatilidade ${ }^{7,8}$. Essas características geram vários problemas como combustão incompleta, formação de depósitos de carbono nos sistemas de injeção, diminuição da eficiência de lubrificação, obstrução nos filtros de óleo e sistemas de injeção, comprometimento da durabilidade do motor ${ }^{9} \mathrm{e}$ emissão de acroleína (substância altamente tóxica e cancerígena) formada pela decomposição térmica do glicerol ${ }^{10}$. Várias abordagens diferentes têm sido consideradas para contornar esses problemas ${ }^{11}$, sendo que a transformação de óleos e gorduras de origens vegetal ou animal em ésteres de álcoois de cadeia curta tem importância estratégica para o setor energético, pois possibilita a obtenção de um produto, o biodiesel, com características físico-químicas semelhantes ao óleo diesel ${ }^{12}$.

Devido ao grande número de ácidos graxos sintetizados pelos seres vivos fica evidente que os óleos vegetais são formados por uma grande variedade de triglicerídeos, cuja composição depende fortemente do tipo de matéria-prima utilizada e das características de cada safra ${ }^{13}$. O ponto de fusão dos triglicerídeos depende da quantidade de insaturações em seus ácidos graxos. Os triglicerídeos líquidos à temperatura ambiente são denominados óleos, que apresentam elevado conteúdo de ácidos graxos insaturados; os triglicerídeos sólidos ou pastosos à temperatura ambiente são conhecidos como gorduras, havendo a predominância de ácidos graxos saturados.

O biodiesel é obtido através da transesterificação (uma reação orgânica na qual um éster é transformado em outro através da troca dos grupos alcóxidos) dos triglicerídeos de óleos e gorduras de origem vegetal ou animal com um mono-álcool de cadeia curta, tipicamente metanol ou etanol, na presença de um catalisador, produzindo uma mistura de ésteres alquílicos de ácidos graxos e glicerol 
Tabela 1. Distribuição de ácidos graxos em alguns óleos e gorduras

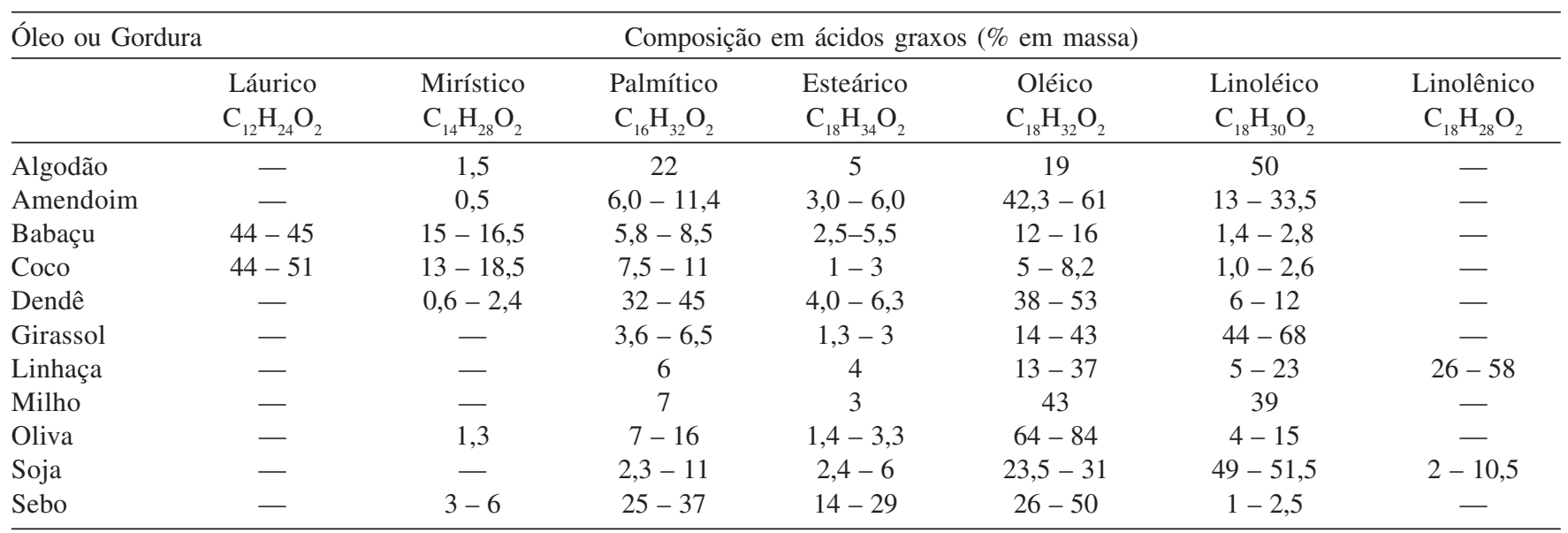

(Figura 1). A princípio, a transesterificação é uma reação reversível. Entretanto, o glicerol formado é praticamente imiscível no biodiesel, reduzindo fortemente a extensão da reação reversa ${ }^{11}$. A imiscibilidade do glicerol no biodiesel é um fator que favorece o rendimento da reação, entretanto, a possibilidade de formação de emulsões estáveis, em certos casos, pode exigir um longo período de repouso para separação das fases de biodiesel e glicerol ${ }^{11}$. A produção de biodiesel por transesterificação é assunto de vários artigos de revisão ${ }^{7,14-16}$, nos quais o papel da catálise e de novos catalisadores é amplamente discutido. Em geral, a transesterificação pode ser catalisada tanto por ácidos como por bases ${ }^{17}$. Entretanto, a reação catalisada por bases (utilizando hidróxido ou alcóxido de sódio ou potássio) apresenta a vantagem de poder ser realizada à temperatura ambiente e, mesmo assim, ser mais rápida que a transesterificação catalisada por ácidos, a qual necessita ser realizada em temperaturas elevadas (ca. $\left.170{ }^{\circ} \mathrm{C}\right)^{18}$.

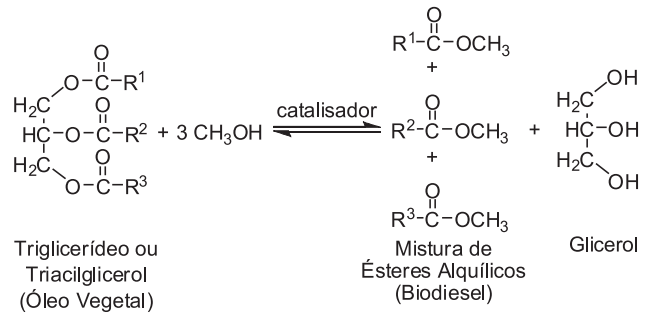

Figura 1. Esquema da transesterificação de um triglicerídeo genérico com metanol

A mistura de ésteres graxos resultante da transesterificação é denominada biodiesel, que é um combustível renovável, biodegradável, que apresenta menor emissão de poluentes, maior ponto de fulgor e maior lubricidade quando comparado ao óleo mineral ou diesel. O biodiesel é perfeitamente miscível ao óleo diesel, podendo ser utilizado puro ou em misturas sem que qualquer adaptação nos motores seja necessária ${ }^{19}$. As misturas binárias de biodiesel e óleo diesel são designadas pela abreviação $\mathrm{B} X$, onde $X$ é a porcentagem de biodiesel adicionada à mistura ${ }^{19}$. A Lei brasileira $11097 / 05$ prevê a obrigatoriedade da adição de $2 \%$ de biodiesel ao diesel (Biodiesel B2) até 2008 e que misturas de 5 a 20\% (B5-B20) se tornem obrigatórias até 2013.

O Programa Nacional de Biodiesel tem sido amplamente divulgado pela mídia, gerando uma possibilidade de contextualização de vários conceitos químicos associados à produção deste combustível alternativo, como a formação/estabilidade de emulsões, viscosidade, catálise, dentre outros. Neste tra- balho, é apresentada a aplicação da atividade de síntese de biodiesel na disciplina de Química Geral Experimental, ministrada no IQ da UNICAMP, para estudantes ingressantes dos cursos de Física e Engenharias Química, Civil e Agrícola. As atividades foram organizadas em 4 aulas consecutivas de $50 \mathrm{~min}$, sendo a primeira dedicada à discussão do tema e dos conceitos para a posterior realização do experimento. $\mathrm{O}$ roteiro experimental envolve algumas dificuldades típicas da produção do biodiesel e permite checar algumas propriedades deste combustível que tanto tem sido discutido atualmente. Em outras propostas experimentais didáticas recentes ${ }^{20,21}$, a transesterificação é feita sob refluxo com vidrarias mais elaboradas. Além disso, o problema da saponificação não é abordado nessas propostas ${ }^{20,21}$, nas quais as reações são feitas em condições em que a formação de sabão é minimizada com o objetivo de facilitar a separação de fases, o que tem caráter meramente ilustrativo. A presente proposta é de transesterificação do óleo de soja refinado com metanol à temperatura ambiente, empregando catálise básica, utilizando vidrarias encontradas comumente em laboratórios de Química. Problemas como formação de sabão e separação de fases são de certa forma estimulados a acontecer pela variação da quantidade de catalisador no meio reacional, para criar questionamentos aos estudantes, que os remetam a refletir sobre os aspectos problemáti$\cos$ da produção do biodiesel. Na seqüência, apresenta-se o roteiro experimental distribuído aos estudantes, que trabalharam em duplas, e também a fundamentação teórica sobre a química da produção do biodiesel por catálise básica. Junto com o roteiro havia um texto explicativo sobre biodiesel e os conceitos químicos discutidos.

\section{ROTEIRO EXPERIMENTAL}

Neste experimento será realizada a síntese do biodiesel a partir da transesterificação de óleo de soja com metanol catalisada por base. O METANOL é um líquido VOLÁTIL, INFLAMÁVEL e TÓXICO, por isso deve ser manipulado na CAPELA e com PÊRA de sucção.

\section{Parte A. Verificando a formação de emulsão e sua estabilidade}

Identifique quatro tubos de ensaio e adicione: (a) $2 \mathrm{~mL}$ de água e $2 \mathrm{~mL}$ de óleo vegetal; (b) $2 \mathrm{~mL}$ de água, $2 \mathrm{~mL}$ de óleo vegetal e 1 gota de detergente; (c) $2 \mathrm{~mL}$ de solução saturada de $\mathrm{NaCl}$ e $2 \mathrm{~mL}$ de óleo vegetal; (d) $2 \mathrm{~mL}$ de solução saturada de $\mathrm{NaCl}, 2 \mathrm{~mL}$ de 
óleo vegetal e 1 gota de detergente. Agite os tubos e deixe-os em repouso por $20 \mathrm{~min}$. Observe o comportamento das fases aquosa e de óleo. Em qual tubo há uma melhor separação de fases?

\section{Parte B. Efeito da quantidade de catalisador na síntese do biodiesel}

Nesta parte do experimento, os estudantes devem se organizar em grupos de 4 duplas. Cada grupo verificará o efeito da quantidade de catalisador na transesterificação do óleo de soja comercial com metanol, preparando várias reações que devem ser conduzidas e observadas paralelamente. Serão usadas as seguintes quantidades de catalisador $(\mathrm{KOH}): 0,50 ; 1,0 ; 2,5$ e $5,0 \% \mathrm{~m} / \mathrm{m}$, considerando $50,0 \mathrm{~g}$ de óleo vegetal.

Em um erlenmeyer de $125 \mathrm{~mL}$ seco, adicione 14,0 $\mathrm{mL}$ de metanol p.a. (CAPELA!!!) e, em seguida, a massa adequada do catalisador. Insira a barra magnética no erlenmeyer, cubra a boca do frasco com papel alumínio e inicie a agitação. (ATENÇÃO: SE SEU AGITADOR TAMBÉM AQUECE, VERIFIQUE QUE O AQUECIMENTO ESTEJA DESLIGADO!!!).

Após a completa dissolução do $\mathrm{KOH}$ no metanol, interrompa a agitação e adicione 50,0 g de óleo de soja ao frasco. Anote suas observações. Cubra novamente a boca do erlenmeyer com papel alumínio. Agite a mistura moderadamente por $30 \mathrm{~min}$. Anote os tempos de mudanças de coloração e homogeneidade da mistura durante a reação.

Transfira o conteúdo do erlenmeyer para uma proveta de 100 $\mathrm{mL}$. Acompanhe a separação de fases por $1 \mathrm{~h}$. Tente identificar em qual mistura há a melhor separação de fases.

Usando uma pipeta graduada, retire 2 alíquotas de $2 \mathrm{~mL}$ da fase inferior e da fase superior. Teste a miscibilidade dessas fases com etanol e hexano (éter de petróleo). Anote suas observações. Qual fase é o biodiesel? Retire $2 \mathrm{~mL}$ da fase de biodiesel e adicione $2 \mathrm{~mL}$ de água. Agite muito levemente a mistura. Anote as características da fase aquosa.

Transfira o restante da fase de biodiesel para uma outra proveta de $100 \mathrm{~mL}$ e adicione pequenas porções de solução saturada de $\mathrm{NaCl}$, agitando suavemente. Espere as fases separarem e reserve para posterior teste de viscosidade.

\section{Parte C. Avaliando o efeito do tempo de transesterificação (opcional)}

Utilizando $1,0 \% \mathrm{~m} / \mathrm{m}$ de hidróxido de potássio repita a síntese do biodiesel. Entretanto, agora usando uma pipeta graduada, colete $4 \mathrm{~mL}$ da mistura reacional nos tempos 0 (logo após inicio da agitação), 1, 2, 3, 4, 10, 20 e 30 min. Transfira essas alíquotas para tubos de ensaio e mantenha-as em repouso. Verifique após 40 min de cada coleta o aspecto da separação de fases, anote suas observações.

\section{Parte D. Estimando as viscosidades relativas do diesel, biodiesel e óleo de soja}

Preencha uma pipeta graduada de $10 \mathrm{~mL}$ com água e meça o tempo de escoamento. Faça esse procedimento em duplicata. Lave a pipeta com etanol e seque-a. Utilizando o biodiesel obtido e lavado com solução saturada de $\mathrm{NaCl}$ (Parte $\mathrm{B}$ ), preencha a pipeta graduada de $10 \mathrm{~mL}$ (limpa e seca) com biodiesel e meça o tempo de escoamento. Faça esse procedimento em duplicata, repetindo tudo para o diesel e para o óleo vegetal. Calcule a razão entre os tempos médios de escoamento do biodiesel, diesel e óleo vegetal e o tempo médio obtido para o escoamento da água, os resultados repre- sentam as viscosidades relativas dos líquidos. Faça uma tabela com todos os resultados e discuta as diferenças de viscosidade relativa.

\section{Parte E. Comparação da queima do biodiesel, do diesel e do óleo de vegetal}

Verifique se não há mais nenhuma reação em andamento ou restos de metanol ao redor de sua bancada. Só depois disso dê inicio ao experimento de queima do biodiesel. Molhe um pequeno pedaço de papel de filtro com biodiesel e com auxílio de uma tenaz de aço inflame o papel no bico de Bunsen. Faça o mesmo para o óleo vegetal e para o diesel. Compare a queima desses líquidos.

\section{RESULTADOS E DISCUSSÃO}

Nesta seção, apresenta-se um material de apoio exclusivo do professor para facilitar a abordagem dos fenômenos envolvidos na síntese do biodiesel.

\section{Parte A. Verificando a formação de uma emulsão e sua estabilidade}

Genericamente, uma emulsão é um sistema disperso no qual as fases são líquidos imiscíveis ou parcialmente miscíveis. As gotículas ou os glóbulos do líquido disperso apresentam geralmente diâmetros de 0,1 a $10 \mu \mathrm{m}$, sendo assim maiores que as partículas encontradas em colóides do tipo sóis ${ }^{22,23}$. Em quase todas as emulsões, uma fase é água e a outra é um líquido apolar, em geral, um óleo. Se o óleo é a fase dispersa, a emulsão é denominada do tipo óleo em água (O/A); se o meio aquoso é a fase dispersa, tem-se uma emulsão do tipo água em óleo (A/O). A aparência das emulsões $\mathrm{O} /$ $\mathrm{A}$ e A/O é diferente. De modo geral, as emulsões $\mathrm{O} / \mathrm{A}$ apresentam uma textura cremosa, enquanto que as emulsões $\mathrm{A} / \mathrm{O}$ apresentam uma aparência gordurosa. A propriedade física mais importante das emulsões, do ponto de vista tecnológico, é sua estabilidade. As gotículas da fase dispersa estão em contínuo movimento aleatório na emulsão. O choque entre essas gotículas pode causar a sua junção, levando à formação de glóbulos maiores que, finalmente, pode levar a fase dispersa a tornar-se uma fase contínua, separada da dispersão por uma única interface. Esse fenômeno é chamado de coalescência. O tempo necessário para ocorrer a quebra da emulsão ou separação de fases varia desde poucos segundos até vários anos, dependendo da formulação da emulsão e das condições de preparação da mesma. A estabilidade das emulsões é facilitada pela presença de agentes emulsionantes, que podem ser desde tensoativos (surfactantes ou detergentes), proteínas ou sólidos finamente divi$\operatorname{didos}^{10}$. O agente emulsionante atua criando um filme ao redor das gotículas que dificulta a coalescência e, conseqüentemente, a separação de fases.

Os fatores fisico-químicos que controlam a formação e a quebra de emulsões são bastante complexos. O objetivo dessa parte do experimento é introduzir o conceito de emulsão e como sua estabilidade pode variar com a adição de outras substâncias ao sistema. Deste modo, 4 dispersões foram preparadas através de agitação vigorosa: (a) água e óleo de soja; (b) água, óleo vegetal com adição de detergente; (c) solução aquosa saturada de $\mathrm{NaCl}$ e óleo soja e (d) solução aquosa saturada de $\mathrm{NaCl}$, óleo de soja e detergente. É possível observar que a presença de detergente, estabiliza a emulsão (b), a qual se mostra estável por mais de $20 \mathrm{~min}$. Entretanto, o detergente não estabiliza a emulsão (d), na qual é possível observar a formação de duas fases distintas em poucos minutos. Essas observações permitem verificar que a solução aquosa saturada de $\mathrm{NaCl}$ apresenta um papel oposto ao da adição de detergente à mis- 
tura. $\mathrm{O}$ detergente leva à estabilização da emulsão, enquanto a solução saturada de $\mathrm{NaCl}$ impede sua formação. A ordem de estabilidade esperada para as emulsões é: (c) $<$ (d) $<$ (a) $<<<$ (b).

Detergente, surfactante e tensoativo são palavras sinônimas utilizadas para descrever substâncias que podem diminuir a tensão interfacial de um sistema ${ }^{23}$. Estas moléculas são anfifílicas, isto é, apresentam uma parte apolar (lipofílica) e outra polar (hidrofílica). A parte polar pode ser catiônica (como um sal quaternário de amônio), aniônica (como um grupo sulfônico) ou ainda não iônica (como um grupo álcool). No Brasil, uma mistura de alquilbenzenossulfonatos é estabelecida como padrão de detergente aniônico biodegradável, sendo que o componente principal dessa mistura é o dodecilbenzenossulfonato de sódio ${ }^{24}$. Em geral, a partir de certa concentração, as moléculas de surfactante formam agregados denominados de micelas (Figura 2), que são gotículas de óleo envoltas por um filme de surfactante, o qual gera uma "capa" polar ou hidrofílica ao redor das gotículas de óleo. No caso de um surfactante iônico, a aproximação das micelas é dificultada pela repulsão eletrostática das cabeças polares, que evita a coalescência, estabilizando a emulsão. A desestabilização da emulsão causada pela presença da solução salina ocorre devido aos íons desta solução competirem pela água de hidratação da cabeça polar do surfactante, o que desestabiliza energeticamente a emulsão, favorecendo a coalescência da fase de óleo dispersa ${ }^{10}$. A adição de um eletrólito diminui a solubilidade de sabões em soluções aquosas; este fenômeno é comumente conhecido como "salting-out" 10 . Na produção de biodiesel, substâncias como sais de ácidos graxos (sabões), mono- e diglicerídeos (também denominados mono- e diacilgliceróis ou mono- e diacilglicerídeos) e fosfolipídeos podem atuar como surfactantes, o que resulta em problemas como o maior tempo de espera para a separação de fases, conforme discutido na seqüência.

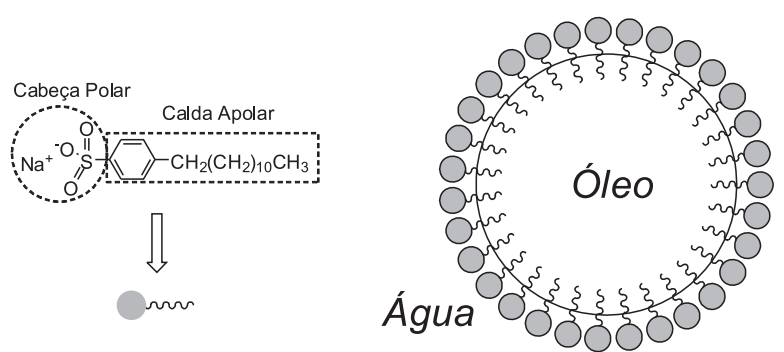

Figura 2. Representação do dodecilbenzenossulfonato de sódio (principio ativo dos detergentes domésticos) e de uma micela

\section{Parte B. Efeito da quantidade de catalisador na síntese do biodiesel}

O termo catálise deriva da palavra grega katálusis que significa dissolução, decomposição, e foi adotado originalmente pelo químico sueco Jöns Jacob Berzelius em 1836, para definir uma substância capaz de modificar a velocidade de uma reação. Em geral, o termo é amplamente utilizado para descrever uma substância que acelera uma reação através de um caminho cineticamente mais favorável, porém o catalisador não participa da estequiometria global da reação, significando que há a possibilidade de recuperálo ao final da reação ${ }^{25}$. Nesta proposta experimental, empregam-se diferentes quantidades de catalisador: $0,5,1,0,2,5$ e $5,0 \% \mathrm{~m} / \mathrm{m}$ de hidróxido de potássio, em relação à massa de óleo.

Durante a reação, observa-se que, inicialmente, a fase alcoólica é imiscível na fase de óleo de soja. Após poucos instantes, as fases tornam-se míscíveis e, em seguida, ocorre a formação de uma emulsão leitosa amarelada (Figura 3). É notório que o aumento da quantidade de catalisador $(\mathrm{KOH})$ gera dispersões mais escuras (Figura $3, \mathrm{t}=0$ ). Observando-se o comportamento da mistura em repouso após a reação, é possível perceber que o aumento da quantidade de catalisador até certo ponto facilita a separação de fases da mistura reacional (Figura 3). Entretanto, após $60 \mathrm{~min}$ de repouso as misturas reacionais contendo 0,50 e $5,0 \% \mathrm{~m} / \mathrm{m}$ de catalisador não apresentam uma boa separação de fases, enquanto que para as misturas em que foram utilizados 1,0 e $2,5 \% \mathrm{~m} / \mathrm{m}$ de catalisador é possível distinguir claramente as interfaces. A fase inferior é constituída de um líquido imiscível em hexano, mas miscível em etanol; enquanto a fase superior é um líquido miscível em ambos os solventes. Essas características levam a concluir que a fase inferior é um líquido polar, o glicerol, e a fase superior é um líquido apolar, o biodiesel. É interessante notar que diferentemente do óleo de soja, o biodiesel é solúvel em metanol ou etanol. Na síntese de biodiesel utiliza-se um excesso do álcool de cadeia curta (6:1) para conduzir a transesterificação em um grau de extensão maior para os ésteres alquílicos ${ }^{18}$. O álcool excedente fica distribuído entre as fases de glicerol e de biodiesel. A remoção do metanol excedente é necessária porque mesmo em baixos teores $(1 \% \mathrm{~m} / \mathrm{m})$, a sua presença pode reduzir o ponto de fulgor fortemente (de 170 para $<40$ $\left.{ }^{\circ} \mathrm{C}\right)^{11}$. Esse abaixamento do ponto de fulgor é um potencial risco à segurança uma vez que o produto pode entrar em combustão em temperaturas mais baixas, tornando-se mais semelhante a uma gasolina (que apresenta ponto de fulgor baixo) ao invés do diesel ${ }^{11}$.

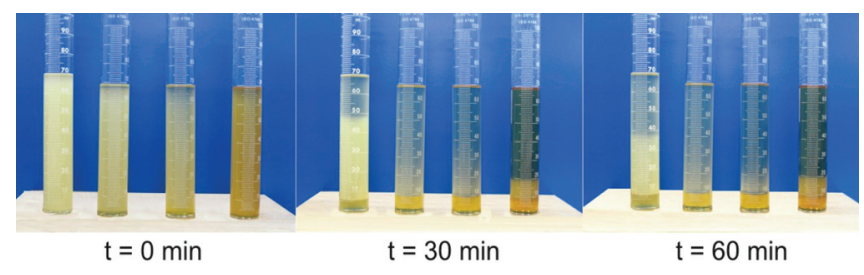

Figura 3. Comportamento da separação de fases com o tempo de repouso em relação à quantidade de catalisador empregada na síntese. As provetas estão dispostas em cada foto, em ordem crescente da quantidade de catalisador $(\%, \mathrm{~m} / \mathrm{m}): 0,50 ; 1,00 ; 2,50 ; 5,00$

A participação do catalisador, $\mathrm{KOH}$, na transesterificação dá-se através da reação entre o metanol com o ânion hidroxila, formando uma quantidade de ânions metóxido no sistema (Equação 1)

$$
\mathrm{CH}_{3} \mathrm{OH}+\mathrm{KOH} \rightleftharpoons \mathrm{CH}_{3} \mathrm{OK}+\mathrm{H}_{2} \mathrm{O}
$$

A transesterificação catalisada por base é uma reação mais rápida, porque o ânion metóxido é nucleófilo muito mais poderoso que o metanol, o que facilita o ataque ao grupo éster do trigilicerídeo, resultando na formação mais rápida do biodiesel (Figura 1). Uma vez que o catalisador atua exclusivamente na cinética da reação, é natural imaginar que o aumento de sua quantidade trará o benefício da reação se processar mais rapidamente. De fato, inicialmente esta idéia é válida, entretanto, a possibilidade de reações paralelas com o catalisador gera subprodutos, diminuindo a seletividade da reação desejada. Isso é indesejável em processos químicos, porque subprodutos implicam em etapas de purificação e, portanto, diminuição do rendimento do processo e aumento do custo do produto.

$\mathrm{Na}$ produção do biodiesel catalisada por base, além da reação de transesterificação (Figura 1), pode ocorrer a saponificação dos ésteres metílicos ou etílicos (biodiesel) ou dos próprios triglicerídeos, através de hidrólise básica. A saponificação é a formação de sabão, isto é, sais de ácidos graxos, o que também pode ocorrer devido a um alto teor de ácidos graxos livres nos óleos 
vegetais ou em óleos utilizados em frituras. O uso dessas matériasprimas é também possível para a produção de biodiesel $^{8}$; entretanto, mudanças no procedimento de reação devem ser feitas devido à presença de água ou de altos teores de ácidos graxos livres. A formação de sabão implica em dois problemas químicos: esta reação consome a base utilizada na catálise da transesterificação do óleo vegetal ou animal com álcool de cadeia curta; a presença de sabão na mistura reacional estabiliza a emulsão biodiesel/glicerol, como observado no caso da emulsão (b), da Parte A, onde havia óleo de soja, água e detergente. Há ainda um problema técnico relacionado ao uso do biodiesel com alto teor de sabão: danos nos motores devido à formação de depósitos e corrosão ${ }^{7}$. Neste roteiro experimental, as altas quantidades de catalisador básico favorecem a saponificação justamente porque na reação da Equação 1, além do ânion metóxido, forma-se também água. Na transesterificação de óleos vegetais, a água tem um papel negativo, principalmente a temperaturas mais elevadas, pois permite a hidrólise dos ésteres de ácidos graxos (triglicerídeos e/ou biodiesel), formando ácidos carboxílicos que são neutralizados pelo catalisador básico, desativando-o e formando sabão. Na Equação 2 é apresentada a equação de saponificação de um éster metílico.

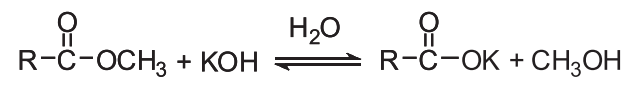

O aumento sucessivo de catalisador no meio, embora acelere a transesterificação (Figura 1), também aumenta a quantidade de água no meio reacional (Equação 1), favorecendo a indesejável hidrólise do biodiesel e/ou do óleo de soja, com formação de sabão (Equação 2). Observa-se na Figura 3, que as dispersões tornam-se cada vez mais amareladas, o que é devido à maior quantidade de sabão na dispersão (uma vez que os carboxilatos são grupos cromóforos com leve absorção na região do visível).

A presença de maior quantidade de sabão também dificulta a separação de fases total da dispersão contendo 5,0\% de catalisador, como evidenciado pela inexistência de uma interface definida entre as fases de glicerol e biodiesel, mesmo após $1 \mathrm{~h}$ de repouso (Figura 3). A maior quantidade de sabão é evidenciada através da adição de água a uma alíquota da fase contendo biodiesel (Figura 4). É possível observar que a maior quantidade de sabão forma uma emulsão com aparência cremosa na parte inferior do tubo de ensaio (Figura 4). É importante destacar que nesse teste não se recomenda agitar fortemente o tubo de ensaio, devido o risco de formar uma emulsão inquebrantável, principalmente para o biodiesel preparado com $5 \%$ de catalisador, o que dificultaria a visualização desejada.

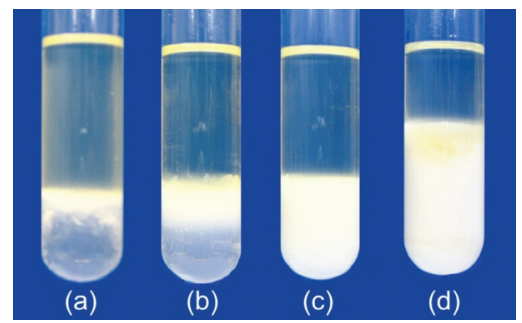

Figura 4. Teste para verificar a presença de sabão, empregando-se (a) 0,50; (b) 1,0; (c) 2,5 e (d) 5,0\% m/m de catalisador nas transesterificações

Industrialmente, utiliza-se a imiscibilidade do biodiesel com água para remover o catalisador da mistura. A presença de sabão no meio reacional favorece a formação de emulsões durante o processo, resultando, na melhor das hipóteses, em longos tempos de separação de fases ou, ao extremo, na formação de uma emulsão inquebrantável. Em geral, foi observado que 1,0\% (m/m) de catalisador produziu um biodiesel com menor quantidade de sabão em nossas aulas. Para permitir que os estudantes avaliassem a viscosidade do biodiesel preparado na Parte B, lava-se a fase de biodiesel com solução saturada de $\mathrm{NaCl}^{22}$, que é eficiente para remoção do catalisador e de parte do metanol não reagido. Entretanto, o sabão é pouco solúvel nessa fase, permanecendo solubilizado na fase de biodiesel em grande parte ${ }^{22}$.

\section{Parte C. Avaliando o efeito do tempo de transesterificação}

Um outro aspecto interessante da transesterificação de óleos vegetais é seu perfil cinético. A transesterificação de triglicerídeos não ocorre em uma única etapa; em geral, os triglicerídeos rapidamente transformam-se em diglicerídeos e monoglicerídeos. Entretanto, a conversão do monoglicerídeo em éster metílico ou etílico constitui uma etapa lenta da reação. A Figura 5 ilustra o perfil cinético típico da transesterificação de um triglicerídeo em termos das concentrações de triglicerídeos, mono- e diglicerídeos e biodiesel $^{11}$ (Figura 5).

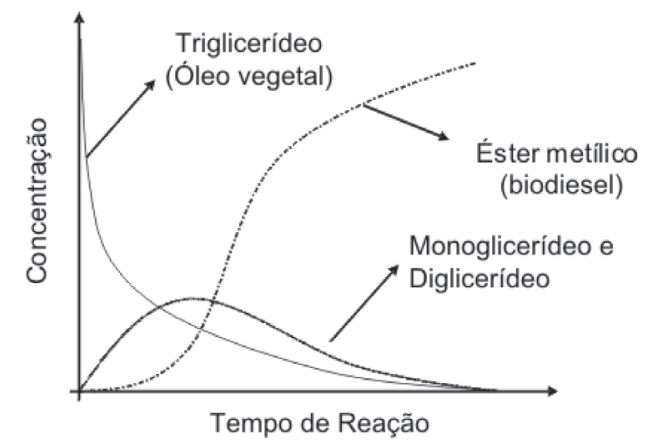

Figura 5. Esquema do perfil cinético da transesterificação de um triglicerídeo. Adaptado da ref. 11

A quantidade de catalisador favorece a cinética da transesterificação, entretanto, como já foi discutido, pode favorecer também a saponificação, principalmente em temperaturas elevadas. $\mathrm{Na}$ Parte B, foi possível notar que $1,0 \% \mathrm{~m} / \mathrm{m}$ de catalisador é suficiente para uma transesterificação completa, com a menor quantidade de sabão formada, levando a uma rápida separação de fases. Entretanto, a reação com apenas $0,50 \%(\mathrm{~m} / \mathrm{m})$ de catalisador gerou uma mistura com pior separação de fases, mesmo contendo pouco sabão (Figura 2). Isto se deve a altas quantidades de monoe diglicerídeos (Figura 6) presentes na mistura, os quais atuam também como surfactante (neste caso não-iônico) que estabiliza a emulsão biodiesel/glicerol, dificultando a separação de fases.

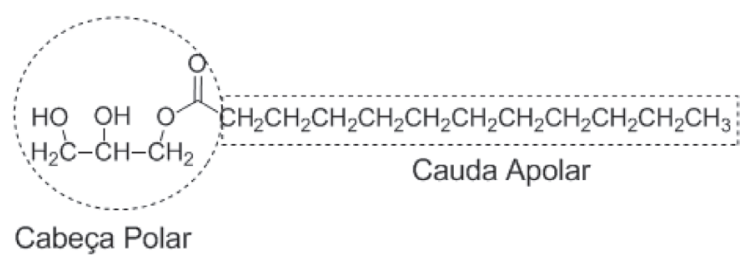

Figura 6. Monoglicerídeo de ácido láurico, um exemplo de surfactante nãoiônico

A Parte $\mathrm{C}$ do experimento ilustra que é necessário certo tempo de reação para que se observe a conversão do óleo vegetal em biodiesel, através da avaliação visual do perfil de separação de fa- 
ses. Uma montagem da bateria de alíquotas coletadas é apresentada na Figura 7, com fotos tiradas após 40 min de repouso de cada alíquota. Observa-se na que para os tempos iniciais da reação há formação de uma emulsão bastante estável e de um volume menor de glicerol (fase inferior). A partir de 20 a 30 min de reação, a separação é bastante eficiente, devido à menor quantidade de monoe diglicerídeos na mistura.

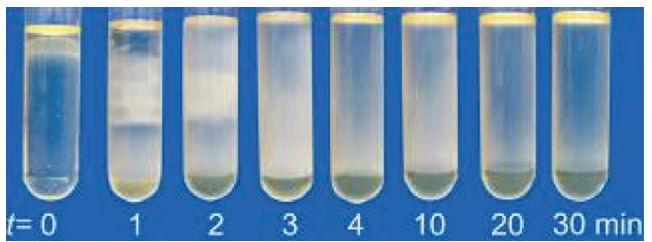

Figura 7. Resultado da separação de fases após 40 min de repouso para as alíquotas tomadas com tempos de agitação de 0, 1, 2, 3, 4, 10, 20 e $30 \mathrm{~min}$

\section{Parte D. Estimando as viscosidades relativas do diesel, biodiesel e óleo de soja}

Viscosidade é a resistência apresentada por um fluido à alteração de sua forma, ou aos movimentos internos de suas moléculas umas em relação às outras. A viscosidade de um fluido indica sua resistência ao escoamento, sendo o inverso da viscosidade a flui$\mathrm{dez}^{26}$. Há várias maneiras de se determinar a viscosidade, sendo bastante utilizada a medida de um fluxo capilar usando um viscosímetro de Ostwald ${ }^{10}$. Embora essa vidraria seja simples, seu custo é relativamente elevado para justificar sua presença em laboratórios de cursos introdutórios de Química. Neste contexto, optou-se por realizar uma estimativa relativa da viscosidade pela medida do tempo de escoamento dos líquidos diesel, biodiesel e óleo de soja em uma pipeta graduada de $10 \mathrm{~mL}$, normalizando-se os resultados com o tempo de escoamento da água. Na Tabela 2 apresentam-se valores médios estimados de viscosidades relativas à água a $25^{\circ} \mathrm{C}$.

Tabela 2. Valores estimados das viscosidades relativas à água a $25{ }^{\circ} \mathrm{C}$

\begin{tabular}{lc}
\hline Líquido & Viscosidade relativa à água a $25{ }^{\circ} \mathrm{C}$ \\
\hline Óleo de soja & 10,3 \\
Diesel & 1,5 \\
Biodiesel $(0,50 \% \mathrm{KOH})$ & 1,7 \\
Biodiesel $(1,0 \% \mathrm{KOH})$ & 1,2 \\
Biodiesel $(2,5 \% \mathrm{KOH})$ & 1,2 \\
Biodiesel $(5,0 \% \mathrm{KOH})$ & 1,5 \\
\hline
\end{tabular}

O óleo de soja apresenta uma viscosidade relativa muito maior que a do diesel. Entretanto, o biodiesel obtido através da transesterificação do óleo de soja com metanol possui uma viscosidade relativa muito semelhante à do óleo diesel. Pensando na viscosidade em termos microscópicos, como as interações intermoleculares dos triglicerídeos e dos ésteres metílicos são de mesma natureza (forças de van der Waals), o maior tamanho molecular do triglicerídeo em relação ao éster metílico é a propriedade que causa a diferença de viscosidade. Como as moléculas do triglicerídeo são maiores, têm grande chance de "enroscarem-se", aumentando a resistência à mudança de forma deste líquido, o que faz com que o óleo de soja apresente uma viscosidade relativa cerca de 10 vezes maior que a do biodiesel ou do diesel. É interessante observar que o biodiesel preparado com diferentes quantidades de catalisador apresenta viscosidades ligeiramente diferentes, devido a distintos teores de sabão e mono- e diglicerídeos presentes no produto final.

\section{Parte E. Comparando a queima do biodiesel e do diesel}

Sem dúvida, o fogo é algo que impressiona o homem desde a antiguidade e tem impacto visual para estudantes e, em condições seguras, é útil para ilustrar propriedades do biodiesel. A queima do biodiesel comparada à do diesel forma menos fuligem, já que o biodiesel não possui compostos aromáticos, os quais, em geral, nas condições cotidianas sofrem combustão incompleta. Outro fato que permite ao biodiesel queimar com menos resíduos de fuligem é o grupo éster que favorece a queima mais completa, produzindo dióxido de carbono e água. Essa característica do biodiesel é muito importante para a qualidade do ar nas grandes cidades, uma vez que a fuligem é em grande parte composta por substâncias poliaromáticas, com grande potencial cancerígeno. O óleo de soja queima com grande dificuldade devido a sua baixa volatilidade quando comparada ao diesel e ao biodiesel.

\section{CONCLUSÕES}

A síntese de biodiesel à temperatura ambiente, proposta neste experimento, é totalmente viável, mesmo em laboratórios com poucos recursos materiais. O desenvolvimento do trabalho laboratorial é simples, fácil e barato, possibilitando aos alunos iniciantes de graduação não somente a ilustração da produção de biodiesel como uma reflexão sobre os problemas enfrentados na transesterificação por catálise básica pela indústria, e algumas propriedades deste combustível alternativo. Não se pretende transformar os estudantes em empresários produtores de biodiesel com este experimento. A proposta visa construir vários conceitos envolvidos na produção e no uso deste combustível alternativo. Assim, problemas como formação de sabão e separação de fases foram, de certa forma, estimulados a acontecer para gerar questionamentos nos estudantes. Certamente, o uso de catalisador (por ex., hidróxido de potássio) acima de $1,0 \% \mathrm{~m} / \mathrm{m}$ não é aconselhável mesmo na transesterificação à temperatura ambiente, porque nestas quantidades o catalisador passa a reagir com os produtos e/ou insumos utilizados na produção de biodiesel. Para óleos e gorduras com altos teores de ácidos graxos livres, o uso de sólidos ácidos como catalisadores é uma promessa inovadora para a área porque não apresentam o problema da formação de sabão ${ }^{16}$. Uma apresentação teórica do que é biodiesel, as reações envolvidas e os problemas relacionados à quebra das emulsões é o embasamento teórico necessário, a ser desenvolvido pelo professor antes do trabalho de laboratório para facilitar o aproveitamento do experimento pelo aluno. A abordagem da síntese do biodiesel é uma possibilidade de contextualização de conceitos como formação de emulsões e sua estabilidade, bem como o fenômeno de catálise que representa uma opção válida de trabalho para estudantes ingressantes no ensino superior. A aplicação da atividade com cerca de 240 alunos em nove turmas de Química Geral Experimental do período diurno foi realizada por 6 docentes no primeiro semestre de 2006. Foram distribuídos questionários para investigação da opinião dos estudantes sobre a atividade e para verificação de impacto pedagógico. As respostas de algumas das 18 questões formuladas indicaram a excelente receptividade dos estudantes à inserção da temática biodiesel na disciplina e permitiram reconhecer a adequação do procedimento experimental de acordo com suas habilidades laboratoriais. Um estudo detalhado sobre os diversos aspectos investigados com este questionário será fruto de trabalho posterior. Os docentes avaliaram aspectos de adequação, viabilidade e correção conceitual da proposta executada e houve consenso quanto à validade de introduzir do experimento na disciplina. Este contexto favorável estimulou a introdução da atividade descrita na seqüência regular de 
experimentos da disciplina, que é oferecida semestralmente pelo Instituto de Química da UNICAMP.

\section{AGRADECIMENTOS}

R. Rinaldi agradece à UNICAMP pela bolsa de doutorado no Programa Piloto de Instrutores Graduados, pois as atividades de docência plena permitiram o desenvolvimento e a aplicação desta proposta. Os autores agradecem à colaboração dos estudantes, dos outros docentes, dos auxiliares didáticos e técnicos envolvidos na disciplina QG102.

\section{REFERÊNCIAS}

1. Zaher, F.A.; Grasas y Aceites 1990, 41, 82.

2. Shay, E. G.; Biomass Bioenergy 1993, 4, 227.

3. http://www.biodieselbr.com/biodiesel/motor-diesel/motor-diesel.htm, acessada em Junho 2006.

4. Gunstone, F. D.; Padley, F. B.; Lipid Technologies and Applications, M. Dekker: New York, 1997, cap. 30 e 31.

5. Schuchardt, U.; Ribeiro, M. L.; Gonçalves, A. R.; Quim. Nova 2001, 24, 247.

6. Streitwieser, A.; Heathcock, C. H.; Kosower, E. M.; Introduction to Organic Chemistry, $4^{\text {th }}$ ed., Macmillan: New York, 1992

7. Pinto, A. C.; Guarieiro, L. L. N.; Rezende, M. J. C.; Ribeiro, N. M.; Torres, E. A.; Lopes, W. A.; Pereira, P. A. P.; de Andrade, J. B.; J. Braz. Chem. Soc. 2005, 16, 1313.

8. Costa Neto, P. R.; Rossi, L. F. S.; Zagonel, G. F.; Ramos, L. P.; Quim. Nova 2000, 23, 531 .

9. Tashtoush, G.; Al-Widyan, M. I.; Al-Shyoukh, A. O.; Appl. Therm. Eng. 2003, 23, 285
10. Schwab, A.W.; Dykstra, G. J.; Selke, E.; Sorenson, S. C.; Pryde, E. H.; J. Am. Oil Chem. Soc. 1988, 65, 1781.

11. Knothe G.; van Gerpen, J.; Krahl, J.; The Biodiesel Handbook, AOCS Press: Champaign, Illinois, 2005, cap. 2 e 4.

12. Tyson, K. S.; Bozell, J.; Wallace, R.; Petersen, E.; Moens, L.; Biomass Oil Analysis: Research Needs and Recommendations, National Renewable Energy Laboratory: Golden, Colorado, 2004.

13. Baumann, H.; Bühler, M.; Fochem, H.; Hirsinger, F.; Zoebelein, H.; Falbe, J.; Angew. Chem., Int. Ed. 1988, 27, 41.

14. Bondioli, P.; Top. Catal. 2004, 27, 77.

15. Hoydonckx, H. E.; De Vos, D. E.; Chavan, S. A.; Jacobs, P. A.; Top. Catal. 2004, 27, 83 .

16. Schuchardt, U.; Sercheli, R.; Vargas, R. M.; J. Braz. Chem. Soc. 1998, 9 , 199.

17. Ferrari, R. A.; Oliveira, V. da S.; Scabio, A.; Quim. Nova 2005, 28, 19.

18. Freedman, B.; Pryde, E. H.; Mounts, T. L.; J. Am. Oil Chem. Soc. 1984, $61,1638$.

19. Parente, E. J. S.; Uma Aventura Tecnológica Num País Engraçado, Unigráfica: Fortaleza, 2003.

20. Clarke, N. R.; Casey, J. P.; Brown, E. D.; Oneyma, E.; Donaghy, K. J.; J. Chem. Educ. 2006, 83, 257.

21. Akers, S. M.; Conkle, J. L.; Thomas, St. N.; Rider, K. B.; J. Chem. Educ. 2006, 83, 260.

22. Shaw, D. J.; Colloid and Surface Chemistry, $4^{\text {th }}$ ed., Butterworth Heinemann: Oxford, 2000, p. 263-269.

23. Jafelicci Jr., M.; Varanda, L. C.; Ouímica Nova na Escola 1999, nº 9, 18

24. Barbosa, A. B.; Silva, R. R.; Química Nova na Escola 1995, nº 2, 3.

25. Daintith, J.; A Dictionary of Chemistry, $4^{\text {th }}$ ed., Oxford University Press: Oxford, 2000, p. 111.

26. http://sbqe2.foco.fae.ufmg.br/viscosidade2, acessada em Junho 2006.

27. Gunstone, F. D.; Harwood, J. L.; Padley, P.; The Lipid Handbook, $2^{\text {nd }}$ ed., Chapman and Hall: London, 1994. 